\title{
MINIMIZING POWER LOSS BY PLACING DG OPTIMALLY IN DISTRIBUTION SYSTEM BY PSO TECHNIQUE
}

\author{
Prakash D B \\ Department of EEE \\ BMSCE, Bengaluru, Karnataka, India
}

\begin{abstract}
This paper presents optimal placement and sizing of Distributed Generation (DG) by using an intelligence technique called Particle Swarm Optimization (PSO). Here the objective function is considered as minimization of active power loss. The proposed methodology is applied and tested for IEEE 33 and IEEE 69 bus radial distribution systems. The result shows that the proposed algorithm is more effective.
\end{abstract}

Keywords - Distributed Generation (DG), Particle Swarm Optimization (PSO), active power loss reduction, Radial Distribution System (RDS).

\section{INTRODUCTION}

In recent years the introduction of DG [1] into the distribution system is growing rapidly, the main reason for this is the increase in demand for load, increasing the loss of delivery and distribution etc. [2] - [3]. The introduction of power electronics also promotes the use of DG in power generation. [4].

There are many DG technologies available on the market, few non-reversible technologies to quote be IC engines. Now the practice of using renewable technologies such as solar PV cells, wind, fuel cells etc. has expanded to generate electricity. The main reason is that they are durable resources and ecofriendly, but there are disadvantages to using these types of system, such as low efficiency, high cost etc. [5] - [6]. Research has continued to overcome these difficulties.

The structure of the distribution system is usually distributed naturally; most RDS have high power losses due to its high resistance to response rates. As a result the efficiency of the system decreases, in order to overcome this problem DG's can be used in the system.

DGs can be classified based on their size as [1]:

Minimum: $1 \mathrm{~W}<5 \mathrm{KW}$;

Small: 5KW <5MW;

Average: $5 \mathrm{MW}<50 \mathrm{MW}$;

Maximum: 50MW <300 MW

Depending on their behaviour can be classified as [7]:
Lakshminarayana C

Department of EEE

BMSCE, Bengaluru, Karnataka, India

Type I: This can only inject real power. Eg. Solar PV, fuel cells, etc. Type II: which can only inject reactive power. Eg. Capacitors, compatible compensators, etc. Type III: is able to inject real and reactive power. Eg. Synchronous machine. Type IV: This can inject active power and absorb reactive power. Eg. Induction generators.

Proper positioning of the DG in the system is very important, planning should be done to reduce energy losses, improve energy profile, improve system reliability etc. Duong Quoc Hung et al. [8] based on the direct loss formula; a method was obtained to determine the objective reduction as objective using the analysis method. Partha Kayal et al. [9] adopted a method of energy reduction and energy development using the PSO process and this approach was tested through various experimental programs. Singh et al. [10] is considered costly as a function of setting different DGs using the MINLP process. However research [11-13] shows that if DGs are not properly designed the flow of electricity occurs which can lead to high systemic losses. A method based on the Genetic Algorithm has been introduced to determine the appropriate size and placement of the DG [14-15]. Prakash [16, 17] used Whale optimization Algorithm for finding optimal placement of DG and capacitor for distribution systems. Satish Kansal et al. [18] looked at the PSO process for the proper placement of different DGs. Authors in [19-21] viewed the multi-objective system as a function used by the PSO and MPSO to place DG's in the system.

This paper introduces PSO based approach to place DG's optimally in distribution network considering power loss minimization as an objective function. The paper is organized as follows: section II addresses about problem formulation, section III is about computational procedure and methodology, section IV discusses about results and discussion and finally section $\mathrm{V}$ concludes the paper.

\section{PROBLEM FORMULATION}

In this paper, total active power loss $\left(P_{L}\right)$ minimization is considered as fitness function and it is represented as shown in equation (1).

$f=\min \left(P_{\text {loss }}\right)$ 
Where, $P_{\text {loss }}=\sum_{q=1}^{k} I_{q}^{2} R_{q}$

Where,

I is the line current at $\mathrm{q}^{\text {th }}$ branch.

$\mathrm{R}$ is the resistance at $\mathrm{q}^{\text {th }}$ branch.

$\mathrm{k}$ is total number of branches.

Subject to the constraints

$$
\begin{aligned}
& 0 \leq P_{d g} \leq \sum P_{\text {load }} \\
& 0 \leq Q_{d g} \leq \sum Q_{\text {load }}
\end{aligned}
$$

And Voltage Constraints as

$V_{\min } \leq V_{i} \leq V_{\max }$

Where $V_{i}$ is the bus voltage at $\mathrm{i}^{\text {th }}$ bus.

\section{COMPUTATIONAL PROCEDURE AND METHODOLOGY}

PSO technique is used to determine the optimal place and size of DG. Forward and backward sweep method is used to find the load flow analysis [22]. Brief explanation of PSO is given in the following section.

PSO technique: - it is developed by Dr. Kennedy and Dr. Eberhart in 1995 [23]. It is a population based on stochastic optimization technique, it was invented by the inspiration of behavior of bird flocking or fish schooling. Swarm is nothing but group of individuals. In this technique individuals change their position with time (here individuals are called particles and positions are called states). Particles fly in n-dimensional search space, during this each particle adjusts its position by its experience (called $\mathrm{P}_{\text {best }}$ ) and also by its neighbor particles (called g gest).

Particle position in n-dimensional vector is represented mathematically as

$$
X_{m}=\left(x_{m 1}, x_{m 2}, x_{m, 3} \times \ldots \ldots x_{m n}\right)
$$

Current position is modified by using

$s_{i d}^{k+1}=s_{i d}^{k}+v_{i d}^{k+1}$

$$
\text { Where } \quad \begin{aligned}
i & =1,2, \ldots \ldots n \\
d & =1,2, \ldots \ldots n
\end{aligned}
$$

$s^{k}=$ Particle's current position.

$s^{k+1}=$ Particle's modified position.

Particle's velocity is also an n-dimensional vector as

$V_{m}=\left(v_{m, 1}, v_{m, 2}, v_{m, j}, \ldots \ldots \ldots v_{m, n}\right)$
Each particle's velocity can be modified by using

$$
\begin{aligned}
& v_{i d}^{k+1}=\omega_{i} v_{i d}^{k}+c_{1} \text { rand } *\left(\text { pbest } t_{i d}-s_{i d}^{k}\right) \\
& +c_{2} \text { rand }\left(g \text { best } t_{i d}-s_{i d}^{k}\right) \\
& \text { Where } \\
& v^{k}=\text { Current velocity. } \\
& v^{k+1}=\text { Modified velocity. } \\
& v_{\text {pbest }}=\text { Velocity based on } P_{\text {best }} \text {. } \\
& v_{\text {gbest }}=\text { Velocity based on } \mathrm{g}_{\text {best }} \text {. } \\
& \mathrm{n}=\text { number of particles } \\
& \mathrm{m}=\text { number of members in particle. } \\
& \omega_{\mathrm{i}}=\text { Weight function. } \\
& c_{i}=\text { Weight coefficient. }
\end{aligned}
$$

In above equation (9) first term is for inertia constant, second term is for local best solution and third term talks about global best solution.

Weight function is given as

$\omega_{\mathrm{i}}=\omega_{\max }-\left(\frac{\omega_{\max }-\omega_{\min }}{k_{\max }}\right) k$

Where $\omega_{\max }$ and $\omega_{\min }$ are max and min weights.

Here $c_{1}, c_{2}$ values are considered as $c_{1}=c_{2}=2$ and $\omega_{\min }=0.4 \quad \omega_{\max }=0.9$ [24].

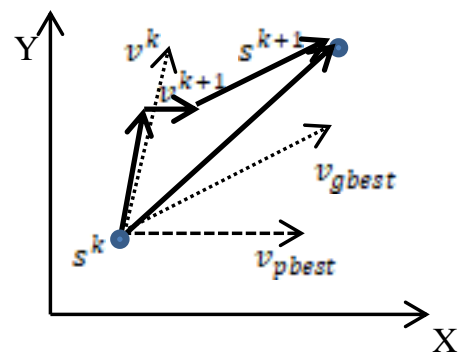

Fig.1. modification of search point by PSO

Fig. 1 shows the modification of search point by PSO and Fig. 2 shows the flow chart for optimal placement and sizing of DG by PSO in distribution system. 


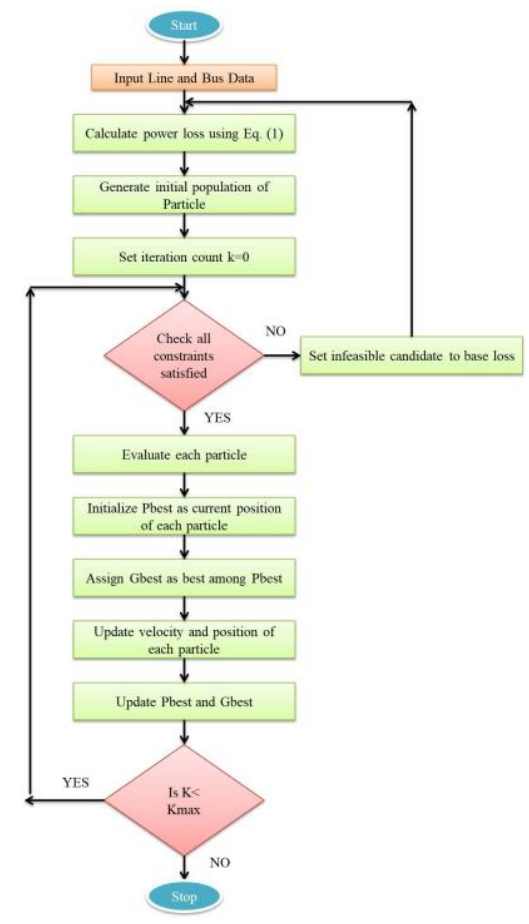

Fig.2.flow chart for suggested method

\section{SIMULATION RESULTS AND ANALYSIS}

Suggested method of placement DG technique has been tested for both 33-bus and 69-bus IEEE distribution test systems. Simulations have been carried out by using Mat-lab 8.1.0 and the results have been discussed below. The base values used for both the distribution systems are 100 MVA as Base MVA and $12.66 \mathrm{KV}$ as Base Voltage. Here the first bus is considered as generation bus and the remaining buses are treated as load buses and these buses are considered for placement of DG.

Case (i):- IEEE 33 bus radial system:-

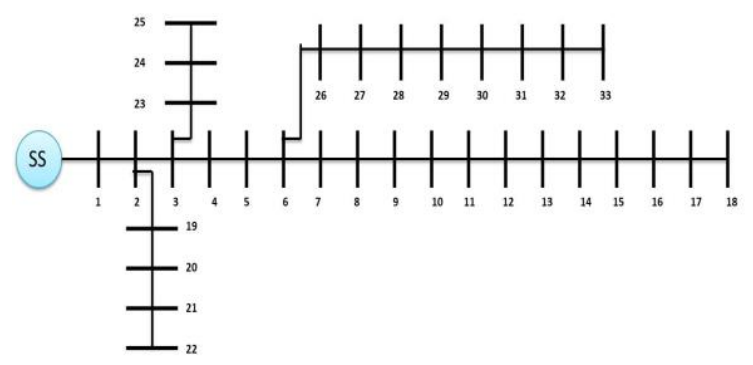

Fig.3. single line diagram of IEEE 33 bus radial distribution system.

The suggested PSO technique has been applied to 33 bus system to determine the optimal size and location of DG in order to achieve the objective function i.e. minimizing power loss. The system line data and bus data are given in [25] with total load of $3.72 \mathrm{MW}$ and 2.3 MVAr.

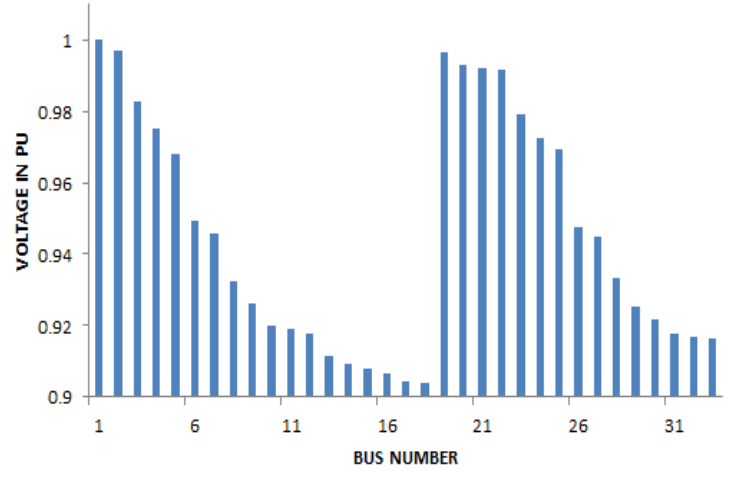

Fig.4. Base case voltages for IEEE 33 bus system.

Fig.3 shows single line diagram of IEEE 33 RDS and Fig.4 shows the voltage profile at different buses without DG. Load flow has been carried out by using forward backward sweep method. From Fig.2, it is observed that minimum voltage obtained is 0.9038 p.u. at bus 18 and total power loss obtained is $210.99 \mathrm{KW}$.

DG has been placed as per the proposed methodology and the optimal location is found to be bus number 6 with size as 2.5582 MW and 1.7611 MVAr. Fig.5 shows voltage profile has been increased after placing DG and new voltage at bus 18 is now increased to 0.9684 p.u. and also total power loss has been drastically reduced to $67.8584 \mathrm{KW}$. Total percentage reduction in power is $67.8381 \%$.

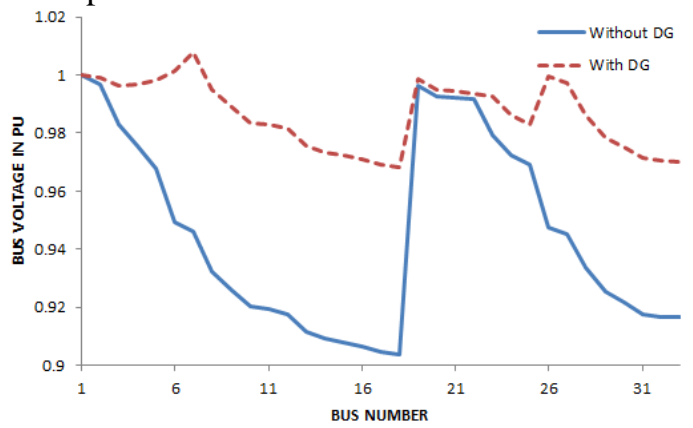

Fig.5. Bus voltages for IEEE 33 bus system.

Case (ii):- IEEE 69 bus radial system:-

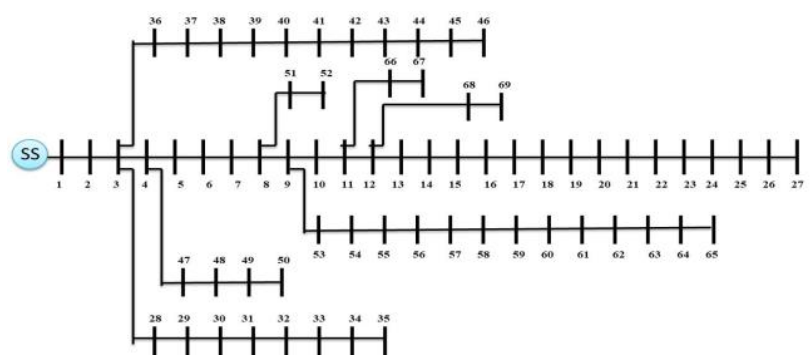


Fig.6. single line diagram of IEEE 69 bus radial distribution system.

Proposed PSO based technique was applied for IEEE 69 bus test system also, to determine the optimal size and placement of DG such that the objective function (1) is minimized. System line data and bus data's are given in [26] with total load of 3.79 MW and 2.69 MVAr.

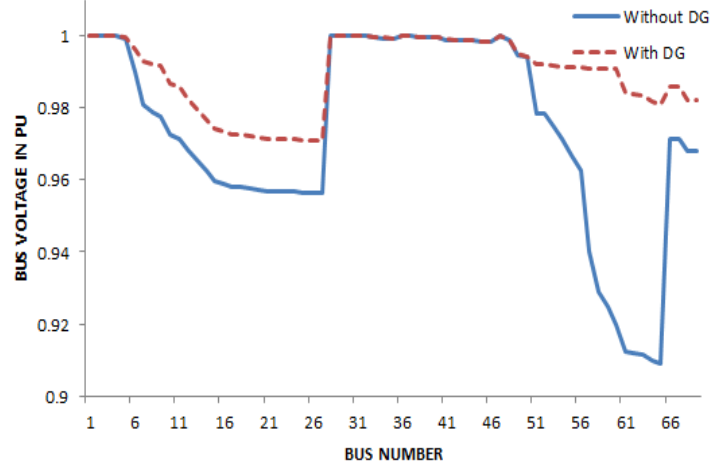

Fig.7. Bus voltages for IEEE 69 bus system.

Fig.6 shows the single line diagram of IEEE 69 bus RDS and Fig.7 shows the voltage profile at different buses for with and without DG. Without DG, minimum voltage is obtained at bus number 65 with 0.9092 p.u. and the total power loss will be $222.92 \mathrm{KW}$. From the proposed method optimal placement will be at bus number 61 with DG size as $1.82 \mathrm{MW}$ and 1.27 MVAr and bus voltages has been increased. Real power loss after placement will be $23.16 \mathrm{KW}$. Therefore total percentage reduction will be $89.70 \%$.

\section{CONCLUSION}

The suggested optimization procedure is tested on IEEE 33 and IEEE 69 bus distribution systems. The results showed that the proposed algorithm is effective for optimal placement of DG by considering objectives as minimization of power loss and constraint as voltage profile improvement.

\section{REFERENCES}

[1] T. Ackermann, G. Anderson and L. Soder. "Distributed Generation: a definition," Electrical Power System Research. 2001, 57(3): 195-204.

[2] D. Singh and R. K. Misra, "Effect of load models in distributed generation planning," IEEE Trans. Power Syst., vol. 22, no. 4, pp. 2204-2212, Nov. 2007.

[3] El-Samahy and E. El-Saadany, "The effect of DG on power quality in a deregulated environment," in Proc. IEEE Power Eng. Soc. Gen. Meet., 2005, vol. 3, pp. 2969-2976.

[4] M. N. Marwali, J. W. Jung, and A. Keyhani, "Stability analysis of load sharing control for distributed generation systems," IEEE Trans. Energy Convers., vol. 22, no. 3, pp. 737-745, Sep. 2007.
[5] W. Li, G. Joos, and J. Belanger, "Real-time simulation of a wind turbine generator coupled with a battery supercapacitor energy storage system," IEEE Trans. Ind. Electron., vol. 57, no. 4, pp. 1137-1145, Apr. 2010.

[6] A. Pigazo, M. Liserre, R. A. Mastromauro, V. M. Moreno, and A. Dell'Aquila, "Wavelet-based islanding detection in grid connected PV systems," IEEE Trans. Ind. Electron., vol. 56, no. 11, pp. 4445-4455, Nov. 2009.

[7] Hung DQ, Mithulananthan N, Bansal RC. "Analytical expressions for DG allocation in primary distribution networks." IEEE Trans Energy Convers.,2010;25(3):814-20.

[8] D. Q. Hung, and N. Mithulananthan, "Multiple Distributed Gneration Placement in primary distribution networks for loss reduction," IEEE Trans. Industrial Electronics, vol. 60, no. 4, pp. 1700-1708, April. 2013.

[9] Patha Kayal and C. K. chanda, "placement of wind and solar based DGs in distribution system for power loss minimization and voltage stability improvement," Electrical Power and Energy Systems, vol. 53,pp.795800, May 2013.

[10] Singh AK, Parida SK. "Combined optimal placement of solar, wind and fuel cell based DGs using AHP." In: Proceedings of world renewable energy congress, Sweden; 2011. pp. 3113-20.

[11] N. Acharya, P. Mahat, and N. Mithulananthan, "An analytical approach for DG allocation in primary distribution network," Int. . Elect. Power Energy Syst., vol. 28, no. 10, pp. 669-678, Dec.2006.

[12] H. L. Willis, "Analytical methods and rules of thumb for modeling DG distribution interaction," in Proc. IEEE Power Eng. Soc. Summer Meet., 2000, vol. 3, pp. 1643 1644.

[13] Y. M. Atwa, E. F. El-Saadany, M. M. A. Salama, and R. Seethapathy, "Optimal renewable resources mix for distribution system energy loss minimization," IEEE Trans. Power Syst., vol. 25, no. 1, pp. 360-370, Feb. 2010.

[14] K. H. Kim, Y. J. Lee, S. B. Rhee, S. K. Lee, and S. K. You, "Dispersed generator placement using fuzzy-GA in distribution systems," in Proc. IEEE Power Eng. Soc. Summer Meet., 2002, vol. 3, pp. 1148-1153.

[15] A. Silvestri, A. Berizzi, and S. Buonanno, "Distributed generation planning using genetic algorithms," in Proc. IEEE Int. Conf. Elect. Power Eng., PowerTech Budapest, 1999, pp. 257.

[16] Prakash D.B, C Lakshminarayana, "Multiple DG placements in radial distribution system for Multi Objectives using Whale Optimization Algorithm", Alexandria Engineering Journal, 57(4), pp: 2797-2806, 2018.

[17] Prakash D.B, C Lakshminaryana, "Optimal siting of capacitors in radial distribution network using Whale 
Optimization Algorithm", Alexandria Engineering Journal, volume 56, issue 4, pp: 499-509, Dec 2017.

[18] Satish kansal, Vishal Kumar and Barjeev Tyagi, “optimal placement of different type of DG sources in distribution networks," Electrical power and Energy Systems, vol.53, 2013, pp.752-760.

[19] Maruthi Prasanna H A, likith Kumar M V, Veeresha A G, Ananthapadmanabha T and Kulkarni A D, "multi objective optimal allocation of a Distributed Generation unit in Distribution network using PSO," ICAECT, 2014,pp.61-66.

[20] D B Prakash, C Lakshminarayana, Multiple DG placements in Distribution Systems for Power Loss Reduction using PSO Algorithm. Procedia Technology, 2016; 25: pp-785-92.

[21] Prakash D.B, C Lakshminarayana, "MPSO based DG and capacitor placement for loss reduction", Journal of Electrical Engineering (JEE), volume 17, issue 2, pp: 289- 294, 2017.

[22] M.H. Haque. "Efficient load flow method for distribution systems with radial or mesh configuration", IET Proc. On Generation, Transmission and Distribution. 1996, 143 (1): 33-38.

[23] J. Kennedy, R.C. Eberhart, "Particle Swarm Optimization", in: Proc. IEEE Conf. on Neural Networks, IV, Piscataway, NJ, 1995, pp. 1942- 1948.

[24] Eberhart RC, Shi Y. "Comparing inertial weights and constriction factor in particle swarm optimization." In: Proceeding of international congress on evaluating computation, San Diego, California. Piscataway, NJ: IEEE service center; 2000. p. 84-8.

[25] Kashem MA, Ganapathy V, Jasmon GB, Buhari MI. "A novel method for loss minimization in distribution networks." In: Proceedings of international conference on electric utility deregulation and restructuring and power technologies, 2000. p. 251-5.
[26] Baran ME, Wu FF. “Optimum sizing of capacitor placed on radial distribution systems." IEEE Trans PWRD $1989 ; 4735-43$

\section{AUTHORS PROFILE}

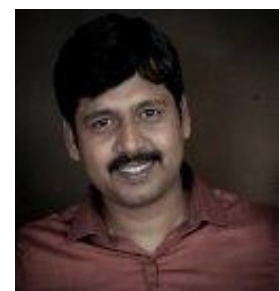

Prakash D B received M.E. and Ph.D. degrees in electrical and electronics engineering from and UVCE and BMSCE Bengaluru, Karnataka, India. Currently he is working as an Assistant Professor in BMSCE, Bengaluru. He has more than 10 years of teaching experience. He published many papers in national and international journals. His research interests include AI techniques to power system, power system operation and control, Renewable energies and DG placement.

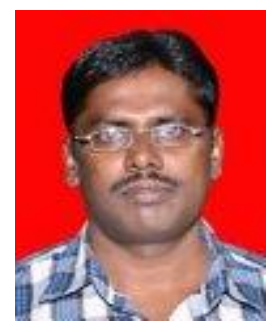

C Lakshminarayana received M.Tech and $\mathrm{Ph} . \mathrm{D}$. degrees in electrical and electronics engineering from NIE Mysore and Anna University, Tamilnadu, India.

$\mathrm{He}$ is currently Professor and Head of department of electrical and electronics engineering in BMSCE, Bengaluru. He has good number of publications in both national and international levels. His interested topic includes PV applications to power system, power system operation and control, Renewable energies. 